\title{
Focos da Aprendizagem Docente: Um Estudo com Professores de Química Ex-Bolsistas do PIBID
}

\section{Focus of Teaching Learning: A Study of Chemistry Teachers Former Participants of PIBID}

\author{
Cássia Emi Obara ${ }^{a}$; Fabiele Cristiane Dias Broietti ${ }^{a}$; Marinez Meneghello Passos ${ }^{b}$ \\ a Departamento de Química, Universidade Estadual de Londrina, Londrina, Brasil - cassiaemi@gmail.com, \\ fabieledias@uel.br \\ b Departamento de Matemática , Universidade Estadual de Londrina, Londrina, Brasil - marinezpassos@uel.br
}

\author{
Palavras-chave: \\ Formação de \\ professores. PIBID. \\ Prática docente. \\ Aprendizagem da \\ docência.
}

Resumo: Poucos artigos relatam contribuições na perspectiva de atuais professores ex-participantes do Programa Institucional de Bolsas de Iniciação à Docência (PIBID). Para compor os dados deste artigo, foram realizadas entrevistas semiestruturadas com ex-bolsistas, egressos do curso de licenciatura em Química e, atuantes na docência, com o objetivo de investigar a contribuição do programa para a aprendizagem docente. Fez-se uso dos Focos da Aprendizagem Docente (FAD), um instrumento analítico que apresenta propostas categóricas. Os sujeitos que mais expressaram Reflexão sobre a Docência são os que possuem maior experiência no magistério. $\mathrm{O}$ Interesse pela Docência e a Identidade Docente estão presentes nas falas de todos os sujeitos, o que mostrou estarem em processo de construção da sua identidade profissional. Desta forma, destacou-se que os entrevistados apresentaram suas primeiras impressões da carreira docente, na condição de profissionais, relacionando a atuação no PIBID como um período de aprendizagem de estratégias didáticopedagógicas diferenciadas e de apreciação à docência.

Keywords: Teacher training. PIBID. Teaching practice. Teaching learning

\begin{abstract}
A few articles report contributions from the perspective of teachers who are former participants of the Institutional Scholarship Program Initiation to Teaching (PIBID). The data of this article was collected by semi-structured interviews with former participants, who were graduates in Chemistry Teaching and are currently working as teachers, aiming to investigate the program's contribution to the teaching learning. Was employed the Teaching Learning Focus (FAD), an analytical tool that presents categorical proposals. The subjects who expressed more Reflection on the Teaching are those with greater experience in teaching. The Interest by Teaching and Teacher's Identity are present in the speeches of all the subjects, which demonstrates the construction of their professional identity process. Thus, it was observed that the interviewed presented their first impressions of the teaching career as professionals, linking their participation in PIBID as a learning period of didactic and pedagogical strategies and assessment to teaching.
\end{abstract}




\section{Introdução}

As discussões sobre formação inicial de professores em um contexto geral e, mais especificamente em Química devem ser consideradas para buscar novas orientações e repensar estratégias de formação adequadas à realidade escolar (GALIAZZI, 2003; MALDANER, 2006; SILVA; SCHNETZLER, 2011; STANZANI, 2012).

Embora contestado, ainda é significativo o número de cursos de licenciatura em Química que, baseados na racionalidade técnica, apresentam uma visão reducionista da atividade docente por meio da aplicação de teorias, culminando em práticas repetitivas alienadas (ECHEVERRÍA et al., 2006; MALDANER, 2006; SILVEIRA; OLIVEIRA, 2009; SILVA; SCHNETZLER, 2011).

As pesquisas também mostram que alguns cursos de licenciatura em Química apresentam três grandes obstáculos: a desarticulação da teoria com a prática; a falta de integração entre universidade e escola e a desvalorização do profissional (SILVEIRA; OLIVEIRA, 2009; MACHADO et al., 2013). Além disso, o desprestígio social da profissão que, de acordo com Galiazzi (2003, p. 52), deve-se à "divulgação dos baixos índices de aproveitamento escolar dos alunos, apontando para a incompetência do professor como única causa, e os salários aviltantes dos professores”, reforça essa desvalorização.

É preciso, portanto, compreender as reais necessidades do professor em sua formação para que ele esteja preparado e saiba intervir no processo de ensino-aprendizagem de forma integrada (SILVEIRA; OLIVEIRA, 2009; MACHADO et al., 2013). Negligenciar a formação inicial pode resultar em profissionais, somente, para o setor industrial e pesquisadores dentro das áreas técnicas específicas, tendo em vista que os diversos saberes do professor devem ser inicialmente construídos durante sua vida universitária, concebendo profissionais autônomos e competentes (SCHNETZLER, 2010).

Um pressuposto apontado para a formação docente é o modelo da racionalidade prática, em que as experiências passam a ser aquilo que sustenta o professor reflexivo, ou o prático reflexivo (SCHÖN, 2000). Este modelo permite contemplar suas ações de forma a julgar as próprias condutas por meio das fundamentações pedagógicas a partir de seus saberes tácitos (ECHEVERRÍA et al., 2006; SCHNETZLER, 2010). Outro ponto ressaltado por Pimenta e Lima (2004) é a valorização do estágio, considerando-o como um campo de conhecimentos necessários ao processo formativo.

Para construir a autonomia dos professores, é importante que licenciandos participem de pesquisas e que, assim, desenvolvam o ato de tomada de decisão de forma a refletir sobre suas ações sob a ótica investigativa (GALIAZZI, 2003). Deste modo: 
sua prática de maneira crítica, de ver sua realidade de sala de aula para além do conhecimento na ação e de responder reflexivamente aos problemas relacionados à profissão docente. (STANZANI, 2012, p. 42).

Desta maneira, falar sobre formação inicial é de fundamental relevância, posto que nesses momentos se discute diversos pressupostos para o desempenho da profissão. Silveira e Oliveira (2009) salientam que os cursos de licenciatura precisam incentivar o processo de construção dos saberes docentes para sua conduta adequada. Assim, é importante que o professor possua domínio dos conteúdos científicos, de tal forma a serem ensinados dentro dos contextos epistemológicos, históricos, sociais, econômicos e políticos.

Outro ponto a evidenciar é a necessidade de motivar o estudante para que ele seja capaz de questionar visões simplistas do processo de ensino-aprendizagem, compreendendo que a construção dos saberes não é linear e atinge um grau de complexidade muito maior. Para isso, o futuro professor precisa saber lidar com o planejamento de aulas; desenvolvê-las; saber analisar suas próprias condutas repensando as práticas quando seu feedback for negativo; conceber reflexões e possíveis soluções para os casos ou aprimorar em situações positivas; avaliar seu aluno ao longo das aulas conforme seu desempenho individual.

Nesse contexto, de incentivos, de valorização e de elevação da qualidade da formação inicial da carreira docente, foi proposto em 2007, em âmbito nacional, o Programa Institucional de Bolsas de Iniciação à Docência (PIBID). Esse Programa apresentava como característica principal antecipar o vínculo entre os futuros educadores e o contexto educacional da Educação Básica, na rede pública, com intuito de promover a articulação entre o Ensino Superior, o Ensino Básico público e os sistemas estaduais e municipais de ensino (STANZANI, 2012).

Além disso, o Programa possibilitava aos licenciandos a convivência com o cotidiano das redes escolares, proporcionando-lhes oportunidades de criação e participação em experiências metodológicas de caráter inovador; a integração entre as Instituições de Ensino Superior (IES) e Ensino Básico; a mobilização dos professores como coformadores dos licenciandos no processo de formação docente e a articulação entre teoria e prática, elevando a qualidade das ações acadêmicas nos cursos de licenciatura (BRASIL, 2010; LIMA, 2012; STANZANI, 2012).

Com o propósito de investigar as contribuições do PIBID como um espaço de discussões e reflexões acerca da profissão docente, neste artigo trazemos alguns resultados provenientes das análises de entrevistas com ex-integrantes do PIBID, egressos do curso de licenciatura em Química de uma universidade estadual do Paraná e que no momento da entrevista atuavam como professores da rede pública. 


\section{A formação de professores e o PIBID}

Stanzani (2012) e Piratelo (2013) realizaram pesquisas evidenciando as contribuições do PIBID como um importante espaço para o incentivo à formação docente, sanando as lacunas deixadas na graduação, além de valorizar as relações entre IES e escola. Este programa permitia a prática reflexiva, levando-os a discutir as ações docentes, seu percurso em sala de aula, moldando um futuro professor crítico de seus próprios atos na escola, desenvolvendo sua identidade docente (SANTOS; ARROIO, 2015).

A familiarização do bolsista com a realidade escolar e as trocas de experiências com os professores das escolas fortalecia o vínculo que o licenciando criava com o ambiente. Piratelo (2013) e Santos e Arroio (2015) citaram o programa como um espaço que atua na formação profissional por meio da pesquisa, sendo visto como comunidade de prática, em que todos os envolvidos aprendiam de forma integrada.

O PIBID diferenciava-se do estágio supervisionado por ser uma proposta não curricular, remunerada, com carga horária maior e que permitia a entrada de bolsistas desde o seu primeiro semestre letivo. Afora essas características, o PIBID possuía, também, como atributo, incentivar a vivência desse bolsista na elaboração das propostas didáticas, tornandoo, portanto, um sujeito ativo no cotidiano das escolas, e os professores, seus coformadores (STANZANI, 2012; PIRATELO, 2013).

É importante ressaltar que o processo de formação do professor pode ocorrer em diversas configurações de aprendizagem, tanto em ambientes formais, como informais (ARRUDA et al., 2013). Os pensamentos advindos da prática mostram que a sala de aula é um ambiente de produção de pesquisa e que não se reduz a 'aplicação de conteúdos' sob uma perspectiva controlada, sistematizada e mecanizada. Ao contrário, as novas tendências de formação de professor preconizam a articulação de distintos saberes, evidenciando o professor como reflexivo de suas práticas e investigações. Além disso, elaborando sua capacidade de assumir os aspectos cognitivos, afetivos, normativos e explicativos que surgem dentro da sala de aula (PIRATELO, 2013).

Por fim, a possibilidade que o PIBID apresenta de movimentar e aproximar universidade e escola, promovendo a abertura de discussões em torno da prática docente e das adversidades encontradas, provém do campo teórico da epistemologia e das estratégias pedagógicas, remodelando a conduta identitária de professores e estudantes da graduação. Fato que pode contribuir para que esses envolvidos passem a refletir sobre suas ações, aproximando delas uma educação mais democrática e crítica (MACHADO et al., 2013). 


\section{Saberes docentes}

O olhar do professor atual é o de seguir em direção ao seu espaço coletivo no qual se encontram diversas necessidades. Para este profissional não mais basta refletir sobre si mesmo é preciso constantemente buscar por novos conhecimentos. Segundo pesquisas como a de Pimenta (2012), para que a escola não perca sua função social, recomenda-se ao educador investir nas demandas da profissão como sujeito envolvido em um contexto sociocultural. Tardif (2014) categoriza os saberes docentes em quatro componentes descritos a seguir:

Os saberes da formação profissional: se referem a saberes institucionalizados na formação docente os quais são incorporados em sua prática. É o conhecimento erudito articulado por meio da formação inicial e continuada, talvez as concepções que normatizam e fundamentam as várias doutrinas pedagógicas "fornecendo, por um lado, um arcabouço ideológico à profissão e, por outro lado, algumas formas de saber-fazer e algumas técnicas" (TARDIF, 2014, p. 37).

Os saberes disciplinares: semelhante aos saberes do conhecimento citado por Pimenta (2012) correspondem às disciplinas ofertadas pelas universidades inseridas nos diversos cursos específicos. Para Tardif (2014) “[...] os saberes das disciplinas emergem da tradição cultural e dos grupos sociais produtores de saberes" (ibid., p. 38).

Os saberes curriculares: esses saberes equivalem aos regimentos provindos da instituição, legislações formalizadas, legitimadas pelo estado em que o professor deve executar. "A instituição escolar categoriza e apresenta os saberes sociais por ela definidos e selecionados como modelos da cultura erudita e de formação para a cultura erudita" (ibid., p. $38)$.

Os saberes experienciais: são saberes que nascem e integram a prática e que são afirmados por ela. Este saber não é doutrinado ou organizado em teorias, "incorporam-se a experiência individual e coletiva sob a forma de habitus e de habilidades, de saber-fazer e de saber-ser" (ibid., p. 39). Possuinte de três objetos a seguir apresentados: "relações e interações que os professores estabelecem e desenvolvem com os demais atores no campo de sua prática; as diversas obrigações e normas as quais seu trabalho deve submeter-se; a instituição enquanto meio organizado e composto de funções diversificadas" (ibid., p. 50). Assim, esses saberes formam "a cultura docente em ação" (ibid., p. 49).

Para finalizar, segundo Tardif (2014), o saber docente é um saber plural e não pode ser separado do trabalho o que implica na interação de seus pares, alunos e outros constituintes da instituição. 


\section{A coleta de dados e o contexto da pesquisa}

Para esta pesquisa, os dados foram coletados por meio de entrevistas semiestruturadas com cinco sujeitos selecionados de acordo com os seguintes critérios: ex-bolsistas PIBID, egresso do curso de licenciatura em Química e que no momento (das entrevistas) atuavam como professores da escola pública.

A opção por esta forma de entrevista justificou-se pela possibilidade de flexibilizar a elaboração de perguntas de modo a permitir improvisar novos questionamentos, caso houvesse algum tipo de depoimento que pudesse enriquecer a pesquisa em desenvolvimento. As perguntas foram formuladas com base em Szymanski (2004) e, posteriormente, apresentadas ao nosso grupo de estudo, efetuando-se uma entrevista piloto para testes.

As questões que serviram de roteiro para a entrevista foram as seguintes: 1. Você se considera professor? Por quê? 2. Você sempre quis isso (ser professor)? 3. Como o PIBID contribuiu para sua formação? 4. Fale um pouco sobre sua trajetória acadêmica até o presente momento. 5. Há quanto tempo você deixou o PIBID e o que significou para você participar do PIBID? 6. Como você vê seu trabalho hoje, como professor/pesquisador, depois de ter participado do PIBID? De que forma o projeto, vinculado ao PIBID de que você participou, contribuiu para o que você é hoje? 7. Qual o papel da sua família na escolha de sua profissão? 8. Em sua opinião, o que foi participar do PIBID? 9. O que mais marcou sua participação no PIBID? Por quê? 10. Você acha que a proposta do PIBID deu certo? Por quê? 11. Você teve dificuldade para trabalhar no PIBID? Como você lidou com essas dificuldades? 12. Você se sente realizado como professor? Contudo, baseando-se nas respostas dos entrevistados, novas questões sugiram e outras foram omitidas.

Os sujeitos entrevistados participaram do Programa em editais distintos, embora as propostas apresentassem semelhança. Na universidade em questão, o programa teve início no ano de 2010 e, naquele momento, o curso de Química apresentou como característica principal de seu subprojeto articular leitura, contextualização e experimentação, tendo como finalidade proporcionar aos bolsistas uma formação inicial fundamentada a partir da prática como pesquisa; contribuir para a formação continuada dos professores do Ensino Médio e possibilitar a esses licenciandos a oportunidade de experimentar metodologias diferenciadas, que auxiliassem na compreensão de conteúdos químicos, associando, dessa forma, ensino, pesquisa e extensão.

Dentre os quarenta e nove estudantes que participaram do primeiro edital do PIBID e dos trinta e oito estudantes que participaram do segundo edital foram selecionados cinco sujeitos (quatro do primeiro edital e um do segundo). O que interferiu no número de sujeitos selecionados foi o requisito licenciado, tendo em vista que o curso apresenta um grande índice 
de reprovação, problema generalizado dentro das licenciaturas de Física, Química e Matemática (ARRUDA, et al., 2006).

Com a realização das entrevistas e após as transcrições, buscou-se nos relatos dos exparticipantes do PIBID, indícios das características dos Focos da Aprendizagem Docente (FAD), assim, assumimos os focos como categorias a priori, já que foram elaborados em um processo anterior às análises dos dados. Utilizamos a Análise Textual Discursiva (ATD) como recurso metodológico e que, segundo Moraes (2003), tem como característica três momentos do processo produtivo de pesquisa, a desordem na qual ocorre a desconstrução do corpus, para depois organizá-lo e dar um novo sentido, acondicionando em unidades de análise; a categorização desses dados que, por consequência, fornecerão fomento para executar a terceira etapa que consiste no surgimento de novas ideias, soluções e teorias, com base na produção interpretativa que tais agrupamentos das informações permitirão construir.

Por fim, a ATD tende para a construção teórica em uma visão hermenêutica de reelaboração de significados a partir das concepções dos sujeitos envolvidos na pesquisa (MORAES; GALIAZZI, 2011). A seguir apresentamos o instrumento utilizado para análise das entrevistas.

\section{Os focos da aprendizagem docente (FAD)}

Os FAD podem ser considerados um híbrido dos Focos da Aprendizagem Científica (FAC) e que tem como origem a proposta do relatório estadunidense publicado no ano de 2009, denominado Learning Science in Informal Environments: People, Places, and Pursuits do National Research Council, NRC (2009). Nesse documento, a esfera de investigação é a aprendizagem informal, ou seja, o aprendizado em ambientes não institucionalizados e por livre escolha (ARRUDA et al., 2013). Para a elaboração dos FAC, a atenção foi atribuída para os "strands of science learning" (NRC, 2009, p. 4, 43), comparadas aos fios de uma corda que se articulam entre si, envolvendo as interações sociais, o ambiente e as experiências de cada um.

As seis habilidades mencionadas no documento (Foco 1 - Desenvolvimento do Interesse pela Ciência; Foco 2 - Compreensão do Conhecimento Científico; Foco 3 Envolvimento com o Raciocínio Científico; Foco 4 - Reflexão sobre a Natureza da Ciência; Foco 5 - Envolvimento com a Prática Científica; e, Foco 6 - Identificação com o Empreendimento Científico) foram denominadas como focos e têm como objetivo captar evidências da fluência científica (ARRUDA et al., 2013).

Conforme novas propostas de pesquisa foram se desenvolvendo ao longo da utilização desse instrumento - os FAC -, outras necessidades começaram a emergir, entre elas, indagações vinculadas à versatilidade desse referencial metodológico dentro dos diversos 
ambientes possíveis para sua aplicação; como adaptá-lo para um ambiente institucionalizado e formal, por exemplo, a sala de aula.

Assim, um análogo dos FAC foi desenvolvido, especialmente, para o campo de formação de professores. A pesquisa de Arruda et al. (2012) veio para propor outra forma de utilização do documento traduzido, sendo então reconstruído dentro de cinco focos na investigação da formação docente - Focos da Aprendizagem Docente (FAD). O que se fez efetivamente, por meio dos FAC, foi capturar significantes das categorias e edificá-las com a roupagem da docência. Para isso, os Focos 2 e 3 dos FAC foram combinados e acondicionados em um só. A seguir, trazemos do artigo original a descrição dos FAD:

\begin{abstract}
Foco 1: Interesse pela Docência. O estudante experimenta interesse, envolvimento emocional, curiosidade, motivação, mobilizando-se para exercer e aprender cada vez mais sobre a docência.

Foco 2: Conhecimento Prático da Docência. A partir do conhecimento na ação e com base na reflexão na ação, o estudante desenvolve o conhecimento de casos, um repertório de experiências didáticas e pedagógicas que orientam a sua prática cotidiana in actu.

Foco 3: Reflexão sobre a Docência. Frente a novos problemas originados de sua prática, os quais não conseguiu resolver no momento em que ocorriam, o futuro professor, com base em instrumentos teóricos, analisa a situação sistematicamente, envolvendo-se com a pesquisa e reflexão a posteriori sobre sua prática e o seu conhecimento acumulado sobre ela, de modo a resolver os problemas inicialmente detectados. Trata-se de desenvolver a dimensão da pesquisa no futuro professor.

Foco 4: Comunidade Docente. O estudante participa de atividades desenvolvidas em uma comunidade docente, aprende as práticas e a linguagem da docência com outros professores ou futuros professores, assimilando valores dessa comunidade e desenvolvendo a reflexão coletiva.

Foco 5: Identidade Docente. O estudante pensa sobre si mesmo como um aprendiz da docência e desenvolve uma identidade como alguém que se tornará futuramente um professor de profissão. (ARRUDA et al., 2012, p. 32-33).
\end{abstract}

No Foco 1 - Interesse pela Docência - estão envolvidos os sentimentos que mobilizaram os entrevistados a aprender sobre a docência. Neste caso, a compreensão da carreira docente pelos sujeitos passa pela motivação e a mobilização para o engajamento desse indivíduo em uma ação. Na pesquisa realizada por Arruda, Passos e Fregolente (2012) e na de Piratelo (2013), os sujeitos eram estudantes de licenciaturas, ainda não formados, porém atuantes em estágios extracurriculares e bolsistas do Programa PIBID, respectivamente.

No nosso caso, foram adotadas tais categorias com o intuito de analisar os depoimentos de professores recém-licenciados, ex-participantes do PIBID. Para isso, ajustouse a descrição da primeira categoria de acordo com os entrevistados - Foco 1 complementando que as falas ali relacionadas dizem respeito ao desenvolvimento do interesse pela docência, bem como a continuidade desse afeto pela profissão docente.

A partir da prática docente o professor desenvolve um saber experiencial, adquirido durante as atividades dentro de sala de aula, acumulando-se em "um repertório de experiências didáticas e pedagógicas que orientam sua prática cotidiana no momento da ação" (ARRUDA et al., 2012, p. 40). Esse saber pode estar relacionado, por exemplo, à transposição 
didática; ao comportamento dos alunos durante a aula; ao improviso, quando o professor é colocado diante de uma situação inesperada e precisa reagir frente a essa situação não habitual; situações que consideramos como o saber fazer. Assim, para os mesmos autores:

Em linhas gerais, poderíamos afirmar que no centro da aprendizagem para a docência encontra-se o desenvolvimento da prática reflexiva, uma concepção que procura considerar que os professores desenvolvem certo conhecimento relacionado diretamente à sua prática (o "conhecimento prático do professor"), fruto de sua experiência e das diversas tentativas de implementar a ação educativa. (ARRUDA et al., 2012, p. 30).

Fatos esses que são destacados por Schön (2000) como momentos reflexivos vivenciados pelo professor: o conhecimento na ação, a reflexão na ação e a reflexão sobre a reflexão na ação. O primeiro, conhecimento na ação, pode estar relacionado a experiências passadas ou o "saber fazer". Já, a reflexão na ação, associa-se à capacidade de responder a circunstâncias in actu, surgidas no momento da aula. A reflexão na ação permite que o professor repense suas convicções em função da realidade vivenciada. E é dentro desses dois primeiros momentos que encontramos o Foco 2 - Conhecimento Prático.

O Foco 3 - Reflexão sobre a Docência - diz respeito às reflexões sobre a docência realizadas após a ação, ou seja, o terceiro momento de Schön (2000) denominado por reflexão sobre a reflexão na ação. Tais análises sobre a prática podem ser ou não profundas, dependendo da perspectiva teórica que o sujeito possui. Esses pensamentos são referentes ao pós-aula, repensando suas práticas, suas atitudes tomadas tentando entender o que aconteceu, autojulgando e autoavaliando. A reflexão, neste caso, é uma aproximação com a atividade investigativa, trata-se do professor pesquisador (PIMENTA, 2005) e que incorpora o foco relacionado à reflexão sobre a prática.

O Foco 4 - Comunidade Docente - tem como característica a participação em uma comunidade de prática que desenvolve reflexões coletivas sobre seu trabalho. Pimenta (2005) aborda a prática reflexiva também como uma prática social, ou seja, a autora indica que as atividades do professor, sua conduta, suas reflexões e avaliações ocorrem por meio da comunidade escolar. Comunidade na qual os professores trocam experiências e vivências de forma a contribuir com o seu repertório de casos conhecidos, fortalecendo-os de forma a trabalharem em conjunto, motivando um ao outro.

A identidade é um tema da formação de professores muito pesquisada por Pimenta e Lima (2004), pois se trata de o sujeito admitir e assumir-se na condição de profissional. Ainda que seja ao longo da sua carreira que o professor constrói a identidade docente, durante sua vida acadêmica, o professor adquire o primeiro contato, a familiaridade com sua atividade profissional e, assim, elabora suas intenções a respeito do seu trabalho. Por esta razão, o Foco 5 - Identidade docente - aparece de forma a apreciar as características que constitui esse professor, para cada sujeito entrevistado. 
Cabe destacar que nesta investigação houve poucos ajustes com a finalidade de enquadrar os metatextos nas categorias apresentadas, considerando que em pesquisas anteriores (já relatadas), as investigações tiveram como sujeitos estudantes de licenciatura. Em função de nossos entrevistados terem terminado a graduação e serem professores recémformados, com tempo de experiência pequeno, assumimos que eles estão em processo de construção de sua identidade profissional. Esses fatos nos remetem a realizar pequenos ajustes nas descrições dos Focos, como pode ser observado na Tabela 1.

\section{Apresentação dos dados e análises}

No ano de 2014 foram realizadas entrevistas com cinco sujeitos, transcritas e analisadas utilizando os FAD. Para assegurar o anonimato, os pesquisados foram codificados, por meio de letras. Cada letra representa um sujeito e segue a ordem das entrevistas: G, A, L, R e P. As falas, após o processo de transcrição, foram enumeradas e colocadas entre colchetes para sua identificação.

Os depoimentos em que se manifestavam mais de uma categoria foram fragmentados, adicionando uma nova sequência numérica, precedida por um ponto. Ao final de cada trecho foram colocados entre parênteses os focos destacados em itálico. Em alguns casos, antecedidos por um traço, adicionou-se uma concisa explicação da categorização. Nos casos em que os relatos de determinado sujeito eram muito longos, mas pertencentes a um mesmo foco, estes foram mantidos sem fragmentação. Segue um exemplo:

\footnotetext{
[A25.1] [...] Mas, assim, eu continuei e, com o tempo, fui me adaptando ao grupo e a fazer, a ir para as escolas, o primeiro dia que eu fui, eu gostei, já, desde o começo. (Foco 1: Interesse pela Docência) - apesar dos contratempos, desde o primeiro contato com a escola já houve uma afinidade com as atividades realizadas. [A25.2] Então, assim, apesar das pessoas falarem que eu tinha vergonha, eu não, eu assim, dentro da sala de aula ou para apresentar um trabalho na faculdade, assim, eu não tinha vergonha de falar em público, assim. (Foco 4: Comunidade Docente) - ao apresentar trabalhos na Universidade e ao dar aulas, sentia-se seguro para falar, ou seja, diante daquela comunidade, ele não se sentia envergonhado. [A25.3] Então, eu fui, eu gostei e continuei participando. (Foco 1: Interesse pela Docência) - gostar das atividades possibilitadas pelo Programa e que remetem à docência.
}

A fala de número 25 do sujeito A foi dividida em três partes: [25.1], [25.2] e [25.3] já que ele aborda inicialmente evidências de interesse no diálogo, demonstrando um envolvimento emocional. Em [25.1] foi apresentado apenas o mais relevante para sua análise, ocultando o restante, considerando que não caberia detalhar a entrevista por completo. Sucedendo seu discurso, o sujeito passou a abordar questões referentes à comunidade, seu envolvimento com o meio, retomando, por fim, o Foco 1 no último trecho.

Para maior entendimento dos FAD, foi construída a Tabela 1 na qual se encontram os focos; a descrição deles adaptada aos sujeitos investigados; um exemplo de depoimento que representa esse foco, sendo apresentados apenas alguns trechos e um comentário que justifica 
o acondicionamento daquele exemplo em determinada categoria. Esta tabela constitui a essência do processo analítico realizado com o corpus da pesquisa, considerando a inviabilidade de expor todos os dados analisados em um artigo.

Ao conduzir a análise neste procedimento descritivo e interpretativo, foi possível direcionar de forma mais esclarecedora a categorização, visto que ainda nos deparamos com o entrelaçamento desses focos em determinadas falas. Considerando sua origem nos strands do NRC (2009) dentro do qual, analogamente, essas categorias são comparadas com os fios de uma corda, unidas entre si, um foco sobressaiu-se em relação aos outros durante a construção da tabela.

Tabela 1 - Os FAD e alguns depoimentos acomodados nas categorias

\begin{tabular}{|c|c|c|c|}
\hline $\begin{array}{l}\text { Foco 1: } \\
\text { Interesse pela } \\
\text { Docência }\end{array}$ & $\begin{array}{l}\text { Descricão: O } \\
\text { recém-formado } \\
\text { experimenta } \\
\text { interesse, } \\
\text { envolvimento } \\
\text { emocional, } \\
\text { curiosidade, } \\
\text { motivação, } \\
\text { mobilizando-se para } \\
\text { exercer e aprender } \\
\text { cada vez mais sobre } \\
\text { a docência. }\end{array}$ & $\begin{array}{l}\text { Exemplo: }[\mathrm{G} 2.2] \text { Aí, } \\
\text { eu vi que era aquilo } \\
\text { que eu gostava, que } \\
\text { era aquilo que eu } \\
\text { queria fazer, que eu } \\
\text { queria trabalhar com } \\
\text { isso. Era o que eu... } \\
\text { era o que eu queria } \\
\text { para mim. Foi a partir } \\
\text { daí. }\end{array}$ & $\begin{array}{l}\text { Justificativa: } \\
\text { Demonstra } \\
\text { entusiasmo pelo } \\
\text { trabalho, o } \\
\text { envolvimento } \\
\text { emocional em } \\
\text { função da afinidade } \\
\text { com a profissão. }\end{array}$ \\
\hline $\begin{array}{l}\text { Foco 2: } \\
\text { Conhecimento } \\
\text { Prático da } \\
\text { Docência }\end{array}$ & $\begin{array}{l}\text { Descricão: A partir } \\
\text { do conhecimento na } \\
\text { ação e com base na } \\
\text { reflexão na ação, o } \\
\text { recém-formado } \\
\text { desenvolve o } \\
\text { conhecimento de } \\
\text { casos, um repertório } \\
\text { de experiências } \\
\text { didáticas e } \\
\text { pedagógicas que } \\
\text { orientam a sua } \\
\text { prática cotidiana in } \\
\text { actu. }\end{array}$ & $\begin{array}{l}\text { Exemplo: [P5] É, } \\
\text { então, no PIBID, nós } \\
\text { tínhamos que fazer } \\
\text { atividades } \\
\text { diferenciadas e, ao } \\
\text { mesmo tempo, de fácil } \\
\text { acesso para que os } \\
\text { nossos alunos } \\
\text { entendessem o que } \\
\text { estávamos querendo } \\
\text { com aquele conteúdo. } \\
\text { E era extrovertido por } \\
\text { causa disso, você } \\
\text { pegava uma coisa que } \\
\text { era do outro mundo, } \\
\text { esmiuçava para ele } \\
\text { entender. Os jogos que } \\
\text { fazíamos, também, } \\
\text { isso, também, } \\
\text { colaborou. }\end{array}$ & $\begin{array}{l}\text { Justificativa: O } \\
\text { sujeito P conta a } \\
\text { respeito de como } \\
\text { era a elaboração } \\
\text { das atividades } \\
\text { realizadas no } \\
\text { PIBID, apontando } \\
\text { não somente sua } \\
\text { satisfação pelas } \\
\text { atitudes tomadas } \\
\text { como também o } \\
\text { resultado de suas } \\
\text { práticas. }\end{array}$ \\
\hline $\begin{array}{c}\text { Foco 3: } \\
\text { Reflexão sobre } \\
\text { a Docência }\end{array}$ & $\begin{array}{l}\text { Descricão: } \text { Frente a } \\
\text { novos problemas } \\
\text { originados de sua } \\
\text { prática, os quais não }\end{array}$ & $\begin{array}{l}\text { Exemplo: }[\text { L9.3] [...] } \\
\text { eu fiz, eu cumpri } \\
\text { metade do conteúdo. E } \\
\text { teve resultado, teve, }\end{array}$ & $\begin{array}{l}\text { Justificativa: } \\
\text { Neste trecho, nota- } \\
\text { se a análise, a sua } \\
\text { autoavaliação e o }\end{array}$ \\
\hline
\end{tabular}




\begin{tabular}{|c|c|c|c|}
\hline & $\begin{array}{l}\text { conseguiu resolver } \\
\text { no momento em que } \\
\text { ocorriam, o } \\
\text { professor recém- } \\
\text { graduado, com base } \\
\text { em instrumentos } \\
\text { teóricos, analisa a } \\
\text { situação } \\
\text { sistematicamente, } \\
\text { envolvendo-se com } \\
\text { a pesquisa e reflexão } \\
\text { a posteriori sobre } \\
\text { sua prática e o seu } \\
\text { conhecimento } \\
\text { acumulado sobre } \\
\text { ela, de modo a } \\
\text { resolver os } \\
\text { problemas } \\
\text { inicialmente } \\
\text { detectados. Trata-se } \\
\text { de desenvolver a } \\
\text { dimensão da } \\
\text { pesquisa. }\end{array}$ & $\begin{array}{l}\text { pra meia dúzia de } \\
\text { alunos. Infelizmente. } \\
\text { Eu não esperava tão } \\
\text { pouco, eu esperava } \\
\text { mais. Porque, } \\
\text { inclusive, como a } \\
\text { gente trabalha em } \\
\text { bloco, essas duas } \\
\text { turmas eu peguei no } \\
\text { meio do ano, agora, } \\
\text { [...]. }\end{array}$ & $\begin{array}{l}\text { feedback do } \\
\text { trabalho realizado } \\
\text { com os alunos. }\end{array}$ \\
\hline $\begin{array}{l}\text { Foco 4: } \\
\text { Comunidade } \\
\text { Docente }\end{array}$ & $\begin{array}{l}\text { Descricão: } \mathrm{O} \\
\text { recém-formado } \\
\text { participa de } \\
\text { atividades } \\
\text { desenvolvidas em } \\
\text { uma comunidade } \\
\text { docente, aprende as } \\
\text { práticas e a } \\
\text { linguagem da } \\
\text { docência com outros } \\
\text { professores, } \\
\text { incorporando } \\
\text { valores dessa } \\
\text { comunidade e } \\
\text { desenvolvendo a } \\
\text { reflexão coletiva. }\end{array}$ & $\begin{array}{l}\text { Exemplo: }[\text { A5] [...] no } \\
\text { final do segundo ano } \\
\text { da faculdade, eu } \\
\text { escrevi meu primeiro } \\
\text { artigo para um } \\
\text { encontro que teve aqui } \\
\text { na universidade. Aí, } \\
\text { no terceiro ano foi o } \\
\text { ano em que a gente } \\
\text { começou a publicar e } \\
\text { participar de } \\
\text { congressos. } \\
\text { Começamos a ir pra } \\
\text { fora, participei de } \\
\text { vários congressos, } \\
\text { publiquei em vários } \\
\text { congressos pelo } \\
\text { PIBID, no terceiro e } \\
\text { quarto ano de } \\
\text { faculdade. }\end{array}$ & $\begin{array}{l}\text { Justificativa: O } \\
\text { sujeito conta sobre } \\
\text { sua participação em } \\
\text { eventos e seu } \\
\text { primeiro contato } \\
\text { com a comunidade } \\
\text { científica da área, } \\
\text { mostrando seu } \\
\text { aumento de } \\
\text { produtividade ao } \\
\text { longo dos anos no } \\
\text { PIBID. }\end{array}$ \\
\hline $\begin{array}{l}\text { Foco 5: } \\
\text { Identidade } \\
\text { Docente }\end{array}$ & $\begin{array}{l}\text { Descricão: } \mathrm{O} \\
\text { recém-formado } \\
\text { pensa sobre si } \\
\text { mesmo como um } \\
\text { aprendiz da } \\
\text { docência e }\end{array}$ & $\begin{array}{l}\text { Exemplo: }[\text { R22.1] [...] } \\
\text { professor tem que tá } \\
\text { envolvido com a } \\
\text { universidade. É difícil } \\
\text { você ficar longe da } \\
\text { universidade e }\end{array}$ & $\begin{array}{l}\text { Justificativa: O } \\
\text { sujeito menciona } \\
\text { como deve ser o } \\
\text { professor, } \\
\text { apontando } \\
\text { características e }\end{array}$ \\
\hline
\end{tabular}




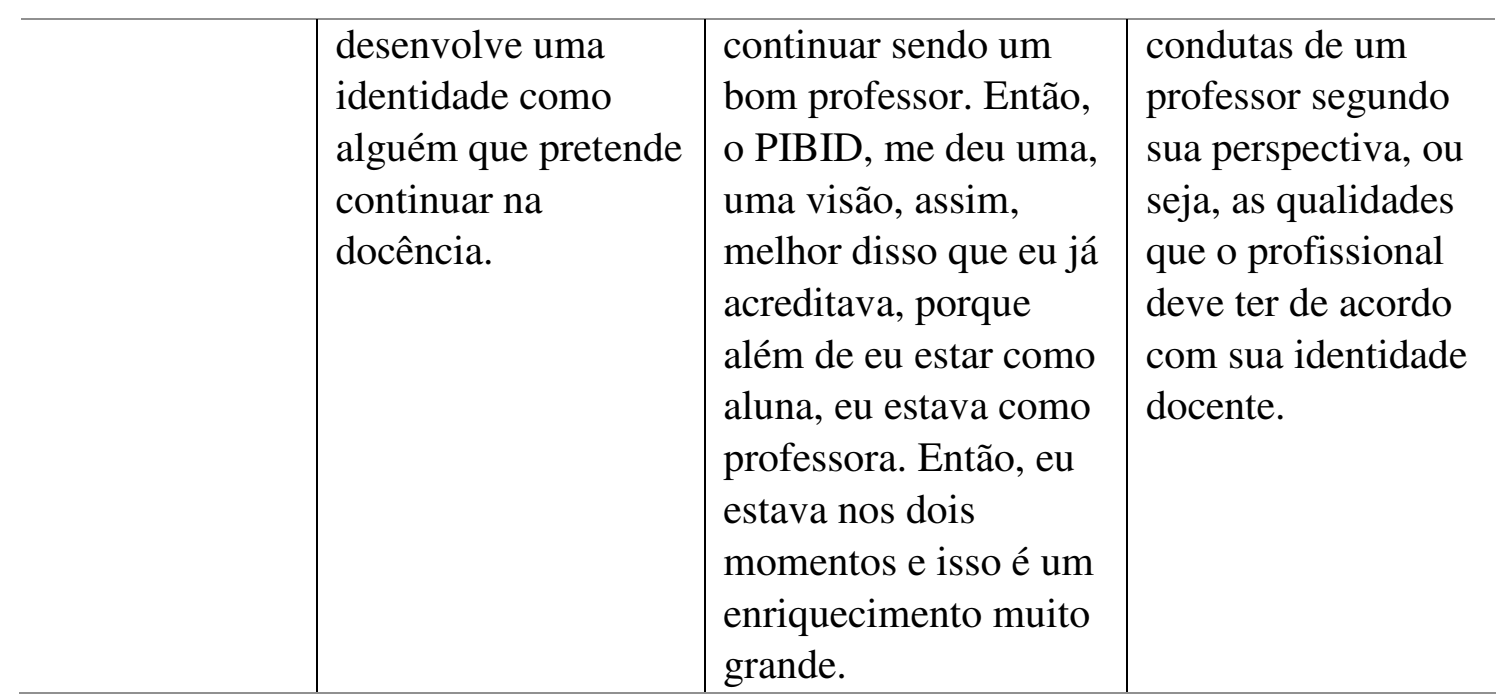

Fonte: os autores

Como indicado foram necessárias algumas alterações nos focos, posto que os FAD inicialmente destinavam-se à iniciação à docência e seus sujeitos, estudantes de licenciatura. Em nossa investigação, trabalhamos com recém-formados que relataram a influência da participação no PIBID para sua vida profissional.

O primeiro, terceiro e quinto exemplos anteriormente alocados são trechos das entrevistas, por esta razão estão codificados diferentemente do segundo e quarto exemplos, nos quais foram mantidas as falas na íntegra, já que elas pertenciam a uma mesma categoria. Portanto, [G2.2] é o segundo fragmento da fala 2 do sujeito G, enquanto [P5] é o quinto depoimento de $\mathrm{P}$ apresentado por inteiro e classificado como Foco 2.

Após as análises das falas dos sujeitos por meio dos FAD, somou-se o total correspondente em cada foco para cada um dos entrevistados. Porém, em razão de possuírem diferentes quantidades de depoimentos categorizados, $\mathrm{G}$ com trinta e oito falas, A com vinte e seis, L com trinta e sete, $\mathrm{R}$ com quarenta e seis e $\mathrm{P}$ com sessenta e nove, apresentou-se também a porcentagem resultante dos relatos dos depoentes, facilitando inclusive comparações entre eles. Por exemplo, do total das falas de G, 36,8\% destinou-se ao Foco 1; 2,6\% dos depoimentos da entrevista estão relacionados ao Foco 2; 13,2\% ao Foco 3; a mesma porcentagem para o Foco 4 e, por fim, 34,2\% ao Foco 5.

O Quadro 1 apresenta as distribuições das falas nos distintos focos, em porcentagem e, entre parênteses, a quantidade de depoimentos categorizados. Ao observarmos as linhas, evidencia-se o entrevistado e os focos que ele mais expressou durante seu discurso, dando uma visão de suas considerações em relação ao PIBID. Ao olharmos as colunas, compara-se a quantidade de relatos manifestada para cada foco entre os sujeitos. Desta maneira, é possível cotejar aquele que mais se revela na categoria, justificando assim o agrupamento de todos os resultados em apenas um quadro. 
Quadro 1 - Distribuição dos relatos nos FAD

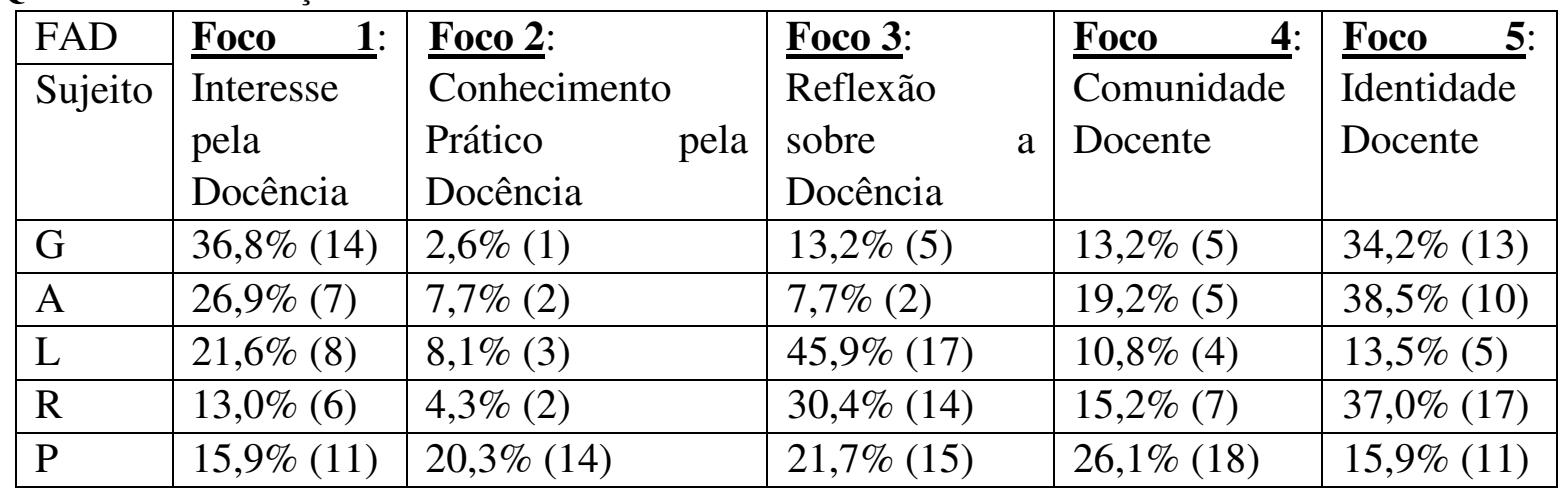

Fonte: os autores

Para o primeiro sujeito, cujos dados podem ser observados na segunda linha do Quadro 1, denominado $G$, a categoria que mais se destacou foi o Foco 1: Interesse pela Docência, seguido do Foco 5: Identidade Docente. Do total de trinta e oito falas analisadas é possível notar que este sujeito indicou gostar da docência e que possuía uma identidade profissional. Atualmente, ele é estudante de mestrado em um Programa de Pós-graduação em Ensino de Ciências. Sua realização profissional foi afirmada após a participação no Programa PIBID, como é possível observar no relato a seguir:

[G2.1] Eu acho que...desde o momento que você... eu passei a me considerar professor quando eu fui para o PIBID. Até antes disso, eu não me considerava. Porque eu fazia licenciatura, só que não era o que eu queria. Não queria ser professora, não queria exercer a profissão, então, eu não me considerava. A partir do momento em que eu comecei a fazer o PIBID, eu comecei a encarar essa realidade de docência, eu me assumi como professora. (Foco 5: Identidade Docente. [G2.2] Aí, eu vi que era aquilo que eu gostava, que era aquilo que eu queria fazer, que eu queria trabalhar com isso. Era o que eu...era o que eu queria para mim. Foi a partir daí. (Foco 1: Interesse pela Docência) - demonstra entusiasmo pelo trabalho, envolvimento emocional.

Dividimos a fala 2 do sujeito $G$ em dois momentos. Em [G2.1] há evidências da Identidade Docente, por tratar de assumir-se como profissional, na descoberta desse momento, quando o universo da docência passou a fazer parte da vida de G. Enquanto que em [G2.2], observamos uma aproximação da identidade pelo gostar de fazer, expressando seu envolvimento emocional com as situações de trabalho.

O segundo sujeito entrevistado, A, apresentou uma proporção maior de falas no Foco 1 (Interesse pela Docência) e Foco 5 (Identidade Docente). O pesquisado A assumiu-se nitidamente como professor e possuía semelhança com $\mathrm{G}$ ao passar a reconhecer a profissão após a entrada no PIBID: [A6.1] "Eu acho que assumi a profissão. Né, assim... assumi a profissão [...]", quando questionado se o PIBID contribuiu para ele sentir-se professor.

Cabe lembrar que no momento da entrevista, A, cursava uma especialização em Ensino de Química e lecionava por meio do processo seletivo simplificado, atualmente (ano de 2016, destacando que as entrevistas foram realizadas em 2014) é estudante de mestrado em 
um Programa de Pós-graduação em Ensino de Ciências. A seguir, a resposta de A ao ser questionado sobre o que de mais importante ele poderia destacar do PIBID:

[A24] [...] o que mais marcou, eu acho que foi a participação em congressos e escrever artigos, publicar, assim, eu gosto muito dessa área, da pesquisa, mesmo, do Ensino, e, assim, a gente ia para as escolas, era um dos objetivos o outro era a parte acadêmica, né, então essa parte foi a que mais me marcou. A parte que eu mais gostei. Nossa, participar de congressos de Ensino, para mim... de escrever artigo, apresentar trabalho, isso tudo para mim, eu gosto muito disso então foi a parte que mais me marcou. (Foco 4: Comunidade Docente) - o momento que mais marcou sua permanência no programa foi participar de congressos e apresentar trabalhos.

Nas falas anteriores identificamos a presença do Foco 4: Comunidade Docente, ou seja, o ato de escrever e compartilhar suas investigações com outros pesquisadores contribuiu, não somente, para a sua formação, mas também para o desenvolvimento do Interesse pela Docência. É nítido observar que existe uma estreita relação entre os Focos da Aprendizagem Docente e que um foco pode levar à constituição e evidenciação do outro. Nesse caso, o foco relacionado à comunidade em que participou, levou também ao interesse, a gostar da profissão.

O terceiro sujeito, L, possuía um histórico profissional um pouco diferente dos dois primeiros. L graduou-se em Química, habilitação bacharelado, atuou no setor industrial e depois ingressou na habilitação em licenciatura. Atualmente, é estudante de mestrado em um programa de pós-graduação de Mestrado Profissional e também ministra aulas no Ensino Médio. Com trinta e sete falas analisadas, destacou-se o Foco 3: Reflexão sobre a Docência, com dezessete trechos relacionados a esta categoria, em seguida, oito sentenças acomodadas no Foco 1: Interesse pela Docência.

Ao longo da entrevista, L ressaltou suas dificuldades na área de Educação, a busca, quase sem sucesso, de uma mudança com relação ao que pode vivenciar e vivencia nas salas de aula. Nestes fragmentos foram colocadas aspas para diferenciá-los dos comentários posteriores: [L12.2] “[...] sou adepta a alguns autores que dizem que a educação no Brasil não tem mais salvação [...] você melhora algo que tem uma base. A educação não tem nem por onde melhorar. [...]". Entretanto, ao mesmo tempo, L permaneceu na área, levando seu mestrado adiante na busca por um caminho: [L12.2] “[...] justamente porque eu quero tentar entender o que está acontecendo, quero tentar fazer alguma coisa que ainda ninguém fez". Essas reflexões acerca do que pensava a respeito da área de Educação no Brasil justificam suas falas estarem em grande parte no Foco 3.

Outro exemplo de reflexão aconteceu ao ser questionado acerca de como o PIBID contribuiu para ampliar as discussões já iniciadas no curso de licenciatura:

[L7]: [...] trouxe alguns conhecimentos que na licenciatura não era possível, eu acho que assim, conhecimentos a mais, mais leitura, mais aprofundamento, sabe? Então, assim como a gente fazia os estudos dos textos, então assim, é... a gente poderia vivenciar aquilo, entendeu? Principalmente porque ia para sala de aula, que no caso, 
assim, estudantes que nunca tinham ido na sala de aula e ainda não estavam fazendo estágio de regência, eu acho, assim, que foi muito bom. E, no meu caso, porque comecei a ter um olhar diferente, né, assim, como eu disse para você, eu dava aula, mas mudou bastante o meu olhar, [...] o PIBID contribuiu muito, só que eu acredito que o objetivo dele ainda na Educação, não está ainda sendo atingido. Não por culpa do Programa, o Programa eu acho assim, é o ideal, o Programa dá conta de suprir muita coisa, mas... tem algumas barreiras ali, que o ensino coloca, que eu acho que não dá conta de passar. (Foco 3: Reflexão sobre a Docência).

Ao longo da entrevista, L mencionou sua insatisfação em relação ao sistema educacional, aqui também identificado. Teceu reflexões acerca das atividades do Programa, e, em seguida, as primeiras mudanças quanto ao ensinar, fazendo com que L passasse a criticar e autoavaliar suas aulas e também apontar alguns problemas encontrados.

O quarto entrevistado, R, também tinha outra graduação, possuía especialização e era o que mais tinha experiência na área, aproximadamente doze anos ministrando aulas. Entrou no programa para tentar avançar com relação às suas dificuldades e desafios encontrados em sala de aula: [R48] “[...] quando eu senti a necessidade, eu fui lá e fiz. Aí, que eu sentia necessidade na sala de aula". Foram quarenta e seis falas analisadas e pelo Quadro 2 é possível identificar que existe uma grande quantidade de falas alocadas no Foco 5: Identidade Docente.

Essa intensidade de depoimentos relacionada ao Foco 5 pode ser justificada não somente pelo tempo de atuação desse depoente como professor, mas também pelo fato de ele estar inserido em uma família que possui muitos professores (avó, mãe, irmãos, tios). Ao retomarmos algumas de suas justificativas e interpelarmos se ele pretendia, profissionalmente, continuar sendo professor, apesar das dificuldades destacadas, ele reafirma:

[R67] Sim, pretendo, ainda pretendo. Mesmo com todas as dificuldades que a cada ano, está muito mais difícil de dar aula, cada ano os alunos chegam com uma bagagem menor e uma, uma, como eu posso te dizer, conduta pior, eu ainda quero continuar dando aula. (Foco 5: Identidade Docente).

No depoimento o sujeito declarou, apesar dos contratempos, que se assumia como professor e que pretendia continuar na carreira e, além disso, almejava preparar-se para um mestrado na área, como revela outro relato: [R26] “[...] para o ano que vem, pretendo entrar no mestrado, né? É o meu próximo passo. Só que estou esperando sair o Mestrado Profissional de Química. Até me interessei pelo mestrado em Ensino de Ciências, mas não é ainda o que eu quero". (Foco 5: Identidade Docente) - o planejamento pelo aprimoramento da carreira. A vontade de dar seu próximo passo, em função do ser professor.

Por fim, temos o sujeito P que possui sessenta e nove falas analisadas; e no Quadro 1 podemos observar que o que mais se destaca em suas discussões é o Foco 4, Comunidade Docente. Quando comenta a respeito de sua formação inicial foi o depoente que mais associou as vivências universitárias com professores do Ensino Superior, das escolas por onde 
passou e fala dos colegas de curso, sendo possível afirmar a influência da comunidade em sua vida profissional. Ele faz referências às suas aulas na época em que era bolsista e na qualidade de professor, comentando sobre suas práticas, refletindo-as. Seu histórico acadêmico era semelhante ao de L, que cursou o bacharelado e, posteriormente, a licenciatura. Mas, ao contrário de L, não possuía experiência em outra área a não ser a docência.

Ao ser questionado sobre o que o PIBID significou para ele, respondeu:

[P17.1] [...] o PIBID contribuiu muito porque eu gostava dele, em 2010 foi o ano que eu fiz muita coisa. (Foco 1: Interesse pela Docência) [P17.2] Fiz o projeto do TCC, fiz o PIBID, ainda mais que tinha que fazer as provas. Foi legal, porque consegui encontrar alguns amigos que tinham interesses em comum e isso contribuiu para montar as atividades, porque você cria um clima de amizade e com esse clima nós montamos várias propostas, fizemos inclusive o 'bingo químico', o twister com perguntas relacionadas à química, as oficinas também sobre o meio ambiente, cada um colaborou de uma forma com as montagens. (Foco 4: Comunidade Docente).

Em um primeiro momento ele demonstrou certo afeto com relação ao Programa, e em [P17.2], ele justificou esse afeto por meio das amizades concebidas e o encontro com esse grupo, permitindo agregar conhecimentos coletivos, promovendo as discussões e desenvolvendo novas propostas para ensinar Química aos alunos do Ensino Médio.

No Quadro 2, apresenta-se a soma das falas dos cinco sujeitos analisados, acomodadas em seus respectivos focos, totalizando duzentos e dezesseis depoimentos. Aqui, novamente, foram descritas por meio de porcentagens as proporções resultantes e entre parênteses seus valores absolutos.

Quadro 2 - Total das falas dos sujeitos acomodadas nos FAD

\begin{tabular}{|c|c|c|c|c|c|}
\hline FAD & $\begin{array}{l}\text { Foco 1: } \\
\text { Interesse } \\
\text { pela } \\
\text { Docência }\end{array}$ & $\begin{array}{l}\text { Foco 2: } \\
\text { Conhecimento } \\
\text { Prático pela } \\
\text { Docência }\end{array}$ & $\begin{array}{l}\frac{\text { Foco 3: }}{\text { Reflexão }} \\
\text { sobre a } \\
\text { Docência }\end{array}$ & $\begin{array}{l}\text { Foco 4: } \\
\text { Comunidad } \\
\text { e Docente }\end{array}$ & $\begin{array}{l}\text { Foco } \\
\text { Identidade } \\
\text { Docente }\end{array}$ \\
\hline $\begin{array}{l}\text { Quantidade } \\
\text { de falas por } \\
\text { foco }\end{array}$ & $\begin{array}{l}20,9 \% \\
(45)\end{array}$ & $\begin{array}{l}14,4 \% \\
(31)\end{array}$ & $\begin{array}{l}19,5 \% \\
(42)\end{array}$ & $\begin{array}{l}19,5 \% \\
(42)\end{array}$ & $\begin{array}{l}26,4 \% \\
(56)\end{array}$ \\
\hline
\end{tabular}

Fonte: os autores

Nota-se maior quantidade de falas no Foco 5 - Identidade Docente -, principalmente pelo fato de os sujeitos R e A possuírem numerosos relatos relativos a essa categoria. Embora apenas dois sujeitos tenham se destacado no Foco 5, os outros também trouxeram depoimentos que foram acomodados neste Foco.

Com menor proporção, L abordou por meio dos resultados de seus relatos que eram mais reflexivos assuntos que remetiam não somente à sala de aula, mas à questões políticas e ao sistema de ensino. É possível também observar que o Interesse pela Docência, Foco 1, esteve presente no discurso de todos, de uma maneira mais equilibrada, quer dizer que todos, de alguma forma, em diferentes graus interessavam-se pela docência. 
Para as respostas à primeira questão da entrevista (Você se considera professor? Por quê?) todos os sujeitos responderam que "sim", afirmando sua identificação com a profissão professor. As justificativas estavam associadas ao assumir-se profissionalmente e também, ao envolvimento e responsabilidade com o processo de ensinar, sendo que três deles, antes de entrar no PIBID, não se consideravam e nem queriam ter como profissão a docência. Foram unânimes os relatos os quais afirmaram a contribuição do Programa com a formação docente, o despertar do interesse pelo ofício familiarizando-se com o ambiente escolar.

Os outros dois sujeitos já atuavam como professores, com maior tempo de trabalho, sendo R com doze anos e L com seis, assim, já possuíam a docência por ocupação diária. Entretanto, ambos apresentaram falas em que afirmaram a contribuição do PIBID para atualizar suas condutas, métodos e estratégias nas aulas.

Esses sujeitos foram mais expressivos na Reflexão sobre a Docência, Foco 3. Esse fato pode estar relacionado à participação deles no PIBID, que tornou suas aulas mais interessantes, apresentando recursos didáticos para conduzi-las de modo inovador. Trazendo, portanto, a possibilidade de realizar uma comparação entre suas atuações em sala antes e depois da participação no PIBID. Além disso, o Programa mostrou a todos um caminho que muitos desconheciam: a pesquisa na área de Ensino de Química, ou seja, o PIBID também contribuiu para formar professores pesquisadores, sendo eles reflexivos sobre a própria prática.

\section{Considerações finais}

Nesta pesquisa, os FAD possibilitaram evidenciar nos depoimentos dos entrevistados o interesse e a mobilização dos depoentes pela carreira docente, envolvendo justificativas pessoais e sociais, tanto de cunho sentimental quanto cognitivo. Um aspecto a ser destacado é o fato de os sujeitos apresentarem suas primeiras impressões a respeito da docência como profissionais, relacionando-as com sua atuação no PIBID na época em que eram estudantes, o que permitiu notar o processo de construção da identidade docente vinculado ao Programa.

Caracterizou-se também que os focos estão entrelaçados uns aos outros, pois possuem fronteiras bem próximas, em que uma categoria pode levar a outra, como, por exemplo, o sujeito $\mathrm{G}$ que, por meio do Interesse pela Docência - Foco 1, passou a desenvolver sua Identidade Docente - Foco 5. Entretanto, alguns focos acabaram se sobressaindo no processo de análise, por possuírem descrições específicas, permitindo a atribuição das falas nas devidas classificações.

A Identidade Docente foi o Foco que mais se destacou, considerando a soma dos cinco entrevistados, seguido do Interesse pela Docência. Todos afirmaram ser professor, assumindo seu papel e apontando características a respeito do que é ser professor na visão de cada um 
deles. Todos, em algum momento, abriram espaço para expressar seu envolvimento emocional com a profissão, o que os levou a falar do Interesse pela Docência, já que a profissão para eles era algo que os faz sentir prazer.

Foi possível, ainda, evidenciar o envolvimento dos entrevistados com a pesquisa em Ensino, momentos esses destacados pelos sujeitos em seus depoimentos, e oportunizados durante a participação no PIBID. Fatos que deflagraram a busca pela continuação dos estudos, principalmente no stricto sensu. Como comentado, anteriormente, na apresentação dos cinco participantes da pesquisa, dois cursavam o mestrado; dois a especialização, com vistas para um futuro mestrado; um deles manifestou a intenção de retomar os estudos e realizar uma pós-graduação.

Em função do que foi coletado por meio das entrevistas e daquilo que as interpretações possibilitaram, pode-se concluir que o PIBID, no caso destes cinco depoentes, cumpriu com seu papel de ampliar o interesse pela profissão docente. Mediante o discurso dos entrevistados evidenciou-se compreensões acerca de seus saberes docentes, caracterizando a docência não só como palco de atividades curriculares em sala de aula, mas como um campo de investigações, explanações e estabelecimento de laços entre escola e universidade.

\section{Referências}

ARRUDA, S. M.; CARVALHO, M. A. de; PASSOS, M. M.; SILVEIRA, F. L. da. Dados Comparativos sobre a Evasão em Física, Matemática, Química e Biologia da Universidade Estadual de Londrina: 1996 a 2004. Caderno Brasileiro de Ensino de Física, v. 23, n. 3, p. 418-438, 2006.

ARRUDA, S. de M.; PASSOS, M. M.; FREGOLENTE, A. Focos da aprendizagem docente. Alexandria - Revista de Educação em Ciência e Tecnologia, v. 5, n. 3, p. 25-48, 2012.

ARRUDA, S. de M.; PASSOS, M. M.; PIZA, C. A. de M.; FELIX, R. A. B. O aprendizado científico no cotidiano. Ciência \& Educação, v. 19, n. 2, p. 481-

$-498,2013$.

BRASIL. Decreto n 7.219 , de 24 de junho de 2010. Dispõe sobre o Programa Institucional de Bolsa de Iniciação à Docência - PIBID e dá outras providências. Diário Oficial da União, Brasília, DF, n. 120, seção 1, p. 4-5, 2010.

ECHEVERRÍA, A. R.; OLIVEIRA, A. S.; TAVARES, D. B.; SANTOS, J. D. A.; SILVA, K. R.; SILVA, R. M. A pesquisa na formação inicial de professores de química. Química Nova na Escola, , n. 24, p. 25-29, 2006.

GALIAZZI, M. do C. Educar pela pesquisa: ambiente de formação de professores de ciências. Ijuí: Unijuí, 2003.

LIMA, M. do S. L. A prática de ensino, o estágio supervisionado e o PIBID: perspectivas e diretrizes para os cursos de licenciatura. In: ENDIPE - ENCONTRO NACIONAL DE 
DIDÁTICA E PRÁTICAS DE ENSINO, 16, 2012, Campinas. Anais... Campinas: Junqueira \& Marin Editores, v. 2. p. 234-246, 2012.

MACHADO, A. R.; LAMBACH, M.; MARQUES, C. A. Formação permanente de professores de Química - contribuições da perspectiva dialógica-problematizadora. In: ENCONTRO DE DEBATES SOBRE O ENSINO DE QUÍMICA, 33, 2013, Ijuí. Anais...Ijuí: Unijuí, 2013.

MALDANER, O. A. A formação inicial e continuada de professores de Química: professores/pesquisadores. 3. ed. Ijuí: Unijuí, 2006.

MORAES, R. Uma tempestade de luz: a compreensão possibilitada pela análise textual discursiva. Ciência \& Educação, v. 9, p. 191-211, 2003.

MORAES, R.; GALIAZZI, M. C. Análise textual discursiva. Ijuí: Unijuí, 2011.

NATIONAL RESEARCH COUNCIL. Learning science in informal environments: people, places, and pursuits. Committee on learning science in informal environments, national research council of the national academies. Washington, DC: The National Academies Press, 2009. Disponível em: <http://www.nap.edu/catalog/12190.html>. Acesso em: 22 set. 2015.

PIMENTA, S. G.; LIMA, M. S. L. Estágio e docência. São Paulo: Cortez, 2004.

PIMENTA, S. G. (Org.). Saberes pedagógicos e atividade docente. 4. ed. São Paulo: Cortez, 2005.

PIMENTA, S.G. Formação de professores: identidade e saberes docentes. In: PIMENTA, S.G. (Org.). Saberes pedagógicos e atividades docentes. 8. ed. São Paulo: Cortez, 2012.

PIRATELO, M. V. M. Um estudo sobre o aprendizado docente no projeto PIBID/UEL licenciatura em Física. 2013. 140f. Dissertação (Mestrado em Ensino de Ciências e Educação Matemática) - Universidade Estadual de Londrina, Londrina. 2013.

SANTOS, V. C.; ARROIO, A. A formação de professores em comunidades de prática: o caso de um grupo de professores de química em formação inicial. Química Nova, v. 38, n. 1, p. 144-150, 2015.

SCHNETZLER, R. P. Alternativas didáticas para a formação Docente em química. In: DALBEN; Â. I. L. F.; DINIZ, J.; LEAL, L.; SANTOS, L. (Org.). Convergências e tensões no campo da formação e do trabalho docente. Belo Horizonte: Autêntica, p. 149-166, 2010.

SCHÖN, D. A. Educando o profissional reflexivo: um novo design para o ensino e a aprendizagem. Tradução Roberto Cataldo Costa. Porto Alegre: Artes Médicas Sul, 2000.

SILVA, R. M. G.; SCHNETZLER, R. P. Estágios curriculares supervisionados de ensino: partilhando experiências formativas. EntreVer, v. 1, p. 116-136, 2011.

SILVEIRA, T. A. da; OLIVEIRA, M. M. de. Formação Inicial e Saberes Docentes no Ensino de Química Através da Utilização do Círculo Hermenêutico-Dialético. In: ENCONTRO NACIONAL DE PESQUISA EM EDUCAÇÃO EM CIÊNCIAS, 7., 2009, Florianópolis, 
Anais... Disponível em: <http://posgrad.fae.ufmg.br/posgrad/viienpec/pdfs/titulos.html>. Acesso em: 5 out. 2015.

STANZANI, E. de L. O Papel do PIBID na Formação Inicial de Professores de Química na Universidade Estadual de Londrina. 2012. 86p. Dissertação (Mestrado em Ensino de Ciências e Educação Matemática) - Universidade Estadual de Londrina, Londrina. 2012.

SZYMANSKI, H. A entrevista na pesquisa em educação: A prática reflexiva. Brasília: Liber Livro Editora, 2004.

TARDIF, M. Saberes Docentes e Formação Profissional. 17 ed. Petrópolis: Vozes, 2014. 325 .

\section{SOBRE AS AUTORAS}

CÁSSIA EMI OBARA. Mestranda em Ensino de Ciências e Matemática (2014) pela Universidade Estadual de Londrina (UEL - PR) e Graduada em Química com habilitação em Licenciatura (2013) pela mesma instituição e Graduada em Bacharelado em Nutrição (2004) pelo Centro Universitário Filadélfia (UniFil - PR). Atualmente é bolsista pela Coordenação de Aperfeiçoamento de Pessoal de Nível Superior (CAPES) e participa do Grupo de Pesquisa em Educação em Ciências e Matemática (EDUCIM) também pela UEL - PR.

FABIELE CRISTIANE DIAS BROIETTI. Licenciada em Química (UEL, 2004), Mestre em Ensino de Ciências e Educação Matemática (UEL, 2008) e Doutora em Educação para a Ciência e a Matemática (UEM, 2013). Atualmente é professora adjunta no Departamento de Química da Universidade Estadual de Londrina e atua no programa de Pós-Graduação em Ensino de Ciências e Educação Matemática. Participou e participa de projetos e programas com foco na formação inicial e continuada de professores, sendo coordenadora de alguns deles. Pesquisa na área de ensino de ciências, atuando principalmente nos seguintes temas: ensino e aprendizagem em química, avaliação e o ensino de química, estratégias metodológicas para o ensino de química e formação de professores.

MARINEZ MENEGHELlo PASSOS. Licenciada e Bacharel em Matemática (UEL, 1982), Mestre em Matemática (UEL, 1989), Mestre em Educação (UEL, 2004) e Doutora em Educação para a Ciência (UNESP, 2009). Atualmente é professora Sênior da Universidade Estadual de Londrina, atuando no programa de pós-graduação em Ensino de Ciências e Educação Matemática. Publicou diversos resultados de suas investigações e das pesquisas realizadas, com os demais membros dos grupos de estudo e de pesquisa dos quais participa em anais de eventos e em artigos em periódicos. Possui dezenas de livros publicados e inúmeros itens de produção técnica. Participou e participa de eventos relativos à sua área de pesquisa. Orientou diversos trabalhos de conclusão de curso na área de Educação, Ciências e Matemática. Participou e participa de diversos projetos na UEL, sendo coordenadora de alguns deles. Nos dias de hoje as temáticas centrais das investigações desenvolvidas são: análise qualitativa, formação de professores e espaços informais de aprendizagem.

Recebido: 10 de fevereiro de 2016.

Revisado: 24 de maio de 2016.

Aceito: 18 de agosto de 2016. 